\title{
External Complexities in Discontinuous Innovation-based R\&D Projects: Analysis of Inter-firm Collaborative Partnerships that Lead to Abundance
}

\begin{abstract}
As a discontinuous technology, nanotechnology is a highly intensive research and development $(R \& D)$ field with a high level of interaction between actors across sectors and international borders. This paper analyses the external complexities that influence the key dimensions of collaborative partnerships in discontinuous innovation-based nanotech $R \& D$ projects across Europe. Drawing on theories of inter-organizational partnerships, we examine the external determinants of size, mechanism, strength, and duration of the cooperative engagements, while controlling their innovative capacity, venture capital (VC) participation, and organizational size. We used mixed research methods to utilize both secondary and primary data, which were derived from the $B v D$ Orbis database, to initially examine nanotech companies and then merged with our survey of 97 top executives and senior administrators of nanotech $R \& D$ projects across 12 European countries. Using multiple and logistic regression models, we show that a predictable legal system, a high level of tolerance for uncertainty, the prevalence of feminine values, geographical and functional nearness to key partners, high level of export demand for high-tech products, and periods of expansionary economic policies all simplify the complexities in the external environment of nanotech $R \& D$ projects. This simplification facilitates highly valuable and long-term inter-firm relationships, producing optimal partnership size with an effective organizational structure. This leads to abundance - the securing of industrial patents and/or the establishment of new product developments.
\end{abstract}

Keywords: Discontinuous technology, R\&D projects, Nanotechnology, Inter-firm collaboration 


\section{Introduction}

The European Commission actively invests into joint $R \& D$ projects ${ }^{1}$, in conjunction with the private sector, to facilitate inter-firm collaboration and scientific performance in an attempt to foster global competitiveness (Paier and Scherngell, 2011). A key challenge for European R\&D policy makers is to define an optimal collaboration scale for fund mobilization across local, regional, national and international cooperative partnerships to promote a vibrant and prosperous socio-economic environment (Muldur et al., 2007). Previous studies view successful inter-firm R\&D collaborative partnerships as voluntary arrangements between organizations, which enhance the development of new innovative products and/or services through the exchange of technology and sharing of expertise (Rosenfeld, 1996; Hagedoorn, 2002; Faems, Looy and Debackere, 2005; Roijakkers and Hagedoorn, 2006; Schleimer and Faems, 2016).

Inter-firm $\mathrm{R} \& \mathrm{D}$ collaboration structures can be measured by assessing the time periods in which the cooperative agreements are fulfilled between joint partners. This ranges from shortterm contracts to medium-term mergers to long-term acquisitions. The governance mechanisms for robust collaborative partnerships in inter-firm $R \& D$ projects require a decentralized command system, which oversees a large amount of funds and organizes a vast amount of human capital in a specialized framework that stimulates useful, innovative engagements among all players (Scandura, 2016; Contractor and Lorange, 2002; Kumar and Dissel, 1996). Collaborative partnerships divert organizational resources away from internal $R \& D$ investments (Park and Kang, 2013). Therefore, it is important that attention is paid to the size of collaborative partnerships in R\&D projects, due to the limited internal resources of the organizations and the complexities in their external environment when participating in joint commercial arrangements.

Nanotechnology is an example of discontinuous innovation. It is a highly intensive research and technological development science-based cluster (OECD, 2014; Sargent Jr, 2016) with complex interdisciplinary features (Schummer, 2004; Rijnsoever and Hessels, 2011). Nanotech enables multiple interactions between scientists from diverse cultural backgrounds (Katz, 1994; Kostoff et al., 2006) working for multi-faceted organizations (Heinze, 2004; Cunningham and Werker, 2012) across public and private sectors (Miyazaki and Islam, 2007) and through internationally regulated borders (Romig Jr. et al., 2007). Academic and industrial actors, as well as governments at all levels (i.e., local, regional, national and international), have allocated a considerable amount of resources to exploring the organizational structure (Fiedler and Welpe, 2010) and the technological (Corbett et al., 2000), socio-economic (Teece, 1993; Cunningham and Werker, 2012), and regulatory (Kica and Bowman, 2012) framework of nanotechnology. They aim to redefine many processes and systems in the near future (Shea, Grinde and Elmslie, 2011).

Most policy initiatives and organizational strategies are geared towards facilitating collaboration, not only on the level of individual scientists (Wagner and Leydesdorff, 2005), but also on a higher level of inter-firm cooperative engagements (Wong, Ho, and Chan, 2007). The merits of inter-firm collaborations in nanotechnology industries are the diversification of risks in an uncertain environment and the transfer of knowledge among cooperative partners (Park and Kang, 2013). It has been found that organizations that are highly involved in collaborative partnerships enhance their competitiveness, experience greater return on their

\footnotetext{
${ }^{1}$ Through its 7th framework programme for research funding which lasted from 2007 to 2013, the EU disbursed $€ 28$ billion and its current Horizon 2020 is estimated at $€ 80$ billion (EU report card, 2017).
} 
investment and enjoy a much higher rate of success (Todeva and Knoke, 2005). Inter-firm relationships can create corporate social capital such as organizational prestige, brand recognition, and reputational status, because inter-firm networks generate intangible assets that can be accumulated through human resources (Beaudry and Allaoui, 2012).

The motivation of our paper was to investigate the main external influencers of effective collaboration in nanotech R\&D projects across Europe. The key contribution of this research paper is to provide policymakers and corporate strategists with useful insights into how to simplify the complexities of the environment in which nanotech firms operate. Our study focuses on examining the major factors that influence the partnership size, governance mechanism, strength and duration of inter-firm relationships among nanotechnology institutions in Europe. We looked intensely at the country's legal origins, cultural dimensions, rates of economic growth, export demand for technologically advanced products, and geographical and functional proximities to industrial and funding partners of nanotech firms; while controlling for their organizational size, $\mathrm{VC}$ participation, and innovative capacity. The key question asked in our study is: how do the external factors affect the dynamics of collaboration in nanotech R\&D projects across Europe?

In this paper, both quantitative and qualitative research methods were used to generate secondary and primary data to enrich the sample and provide adequate observational data for the analysis. We collected secondary data on nanotechnology organizations and their industry affiliations, organizational size (total assets), number of patents, and VC participation from the Orbis database provided by Bureau van Dijk (BvD). As we were unable to find useful proxies for collaborative dynamics of nanotechnology organization in the secondary dataset, we then used a survey instrument to generate vital interview and questionnaire data. Finally, we included the legal origin index developed by La Porta et al. $(1999 ; 2000)$ for all the nanotech $\mathrm{R} \& \mathrm{D}$ projects in the dataset, and carried out ordinary least square (OLS) and logistic regressions to provide empirical tests for our hypotheses.

The results show that external factors - such as the geographical and functional proximities to key partners, a country's legal origin, cultural dimensions, economic growth and its export demand for advanced high-tech products - meaningfully influence the size and governance mechanism, strength and duration of collaboration in nanotech $R \& D$ projects. The closeness, regarding geography and functional space, of nanotech $R \& D$ firms most influences the dimensions of their $R \& D$ collaborations. Also, nanotech firms operating in countries with French Civil Law origin are inclined to establish a centralized system of governance in their R\&D collaborative partnerships, due to the high level of legal predictability. Countries with a legal origin in English Common Law are less predictable, while those with French Civil Law are less flexible (Beck et al., 2003). We also find that VC funding in nanotech R\&D projects usually leads to VC's active participation in the strategic management of these collaborative partnerships, in particular to influence the size and duration of the cooperative engagements.

Moreover, our results show that the innovative capacity and organizational size of nanotech firms also affect the dimensions of their R\&D collaborations (Fiedler and Welpe (2010). We argue that, because nanotech $R \& D$ projects are inherently very complex, nanotech firms that operate with a more decentralized internal organizational structure and in a simpler external environmental framework will be more effective in their R\&D collaborations and hence can produce better innovative outcomes for a more abundant world. Our study concludes by identifying the possible opportunities and challenges for policy makers and organizational 
strategists to exploit or guard against, to enhance the dimensions of collaboration within the nanotechnology industry or similar emerging and discontinuous innovations.

The paper is structured as follows: In section 2 we introduce the theoretical framework of the study and develop the hypothesis. Section 3 outlines the research methodology. The empirical results are presented in section 4 . The section 5 discusses these results and highlights research and policy implications. Section 6 concludes with the paper's contributions and its limitations and suggests for further research.

\section{Theoretical Framework}

Inter-firm relations management capabilities can be defined as the structure, processes, and tools that equip companies to seize, distribute, accumulate and use information gathered from the collaborative activities carried out with other partners (Niesten and Jolink, 2015). Interfirm relations management capabilities are vital determinants of effective collaboration, because they allow the partners in a cooperative arrangement to easily modify the key features of their relationship to mitigate any unforeseen external threat to it. Collaborative arrangements help reduce $R \& D$ costs and mitigate business risks in new projects. Partners with a higher level of inter-firm relations management capabilities tend to influence partners with lower levels in any collaborative partnership (Contractor and Lorange, 2002).

\subsection{Strength and duration of collaborative partnerships}

Figure 1 depicts a proposed model for the relationships between the strength and duration of a collaboration and the size of the cooperative partnership. We see from the model below that the greater the strength and the longer the duration of $R \& D$ collaboration, the lesser the number of their partners. As the strength and duration increases, the sizes of both industrial and overall partners will most likely decrease, based on the interaction effects between the two variables. Thus, as a policy implication we can infer that for collaborative partnerships in high-tech industries to be strong and lasting, the number of the partners must be reduced to the most optimal level.

\section{Figure 1: A proposed model for the strength and duration of collaborative partnerships}

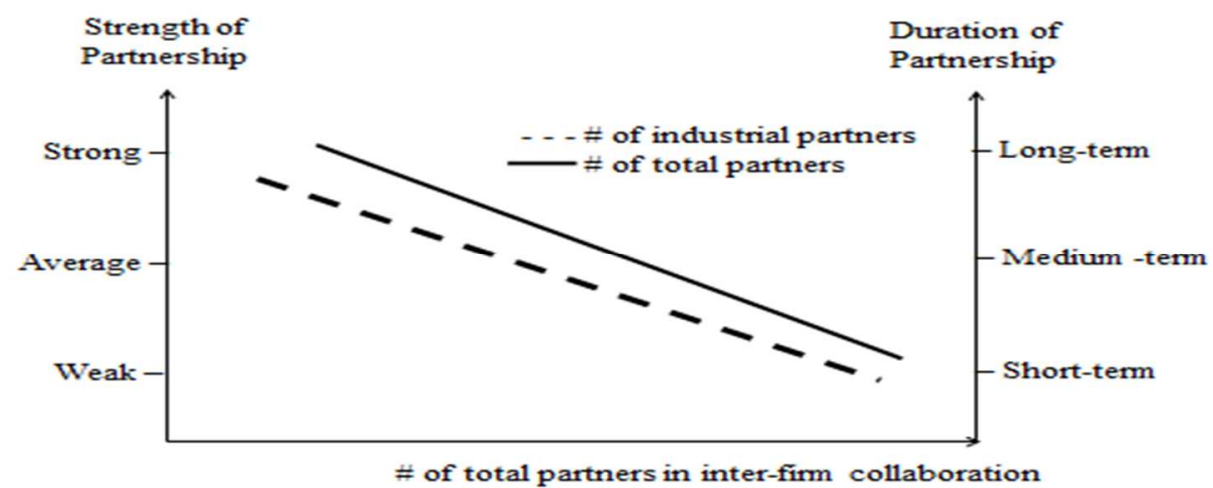

In our model above, we illustrate that effective inter-firm collaboration is dependent not only on the number of partners but also on the quality of input delivered into the nanotech $R \& D$ projects over a sustained period of time. Our proposed model is based on the data sample of 
this study. It was constructed from the relationships between three of our dependent variables, taking into account the partner's size, the strength of the value network and the duration for completing the R\&D projects. We observe that the strength of partners decreases from strong to weak the more partners a company has, because R\&D projects tend to explore multiple concepts initially and later focus on a few productive trends that guarantee fast innovative outcomes. Also, the duration of partnership decreases from long-term to short-term the more partners a company has, because as R\&D projects become more successful through the patenting of new ideas or development of new products, a centralized governance mechanism emerges and reduces the need for more industrial partners.

\subsection{Proximity as an influencer of $R \& D$ collaboration}

Proximity is considered to be the closeness between two economic actors in terms of their distance, network and firm size (Boschma, 2005). Collaborations in European nanotech companies are not random and are facilitated by different kinds of proximities such as organizational, technological, geographical, functional, cognitive, sectoral and social proximity (Cunningham and Werker, 2012). Social network and spatial or geographical proximity have an important influence on the level of $R \& D$ collaboration among nanotech companies (Autant-Bernard et al., 2007). On the other hand, the physical closeness between collaborators is more important when there are institutional differences (Ponds et al., 2007). However, due to advances in information and communication technologies, the physical distance between companies does not singularly affect their ability to collaborate in $R \& D$ projects (Torre, 2008). Nevertheless, informal and face-to-face interaction among scientists is critical in facilitating research collaborations (Katz, 1994; Balland, 2012). The time and cost it takes to interact are more important than the pure distance between collaborators (Lundquist and Trippl, 2013). The functional linkages or proximity among cooperative partners facilitates their performance (Koch and Strotmann, 2006).

One of the main reasons for the surge in scientific research collaborations is due to the growth in interdisciplinary research institutes, which rely on the combination of the expertise of researchers from different fields of study. Scientific activities are organized by individuals or organizations that operate under local, regional, national and international institutions at various levels of spatial proximity, and who are in communication with one another to create and diffuse scientific knowledge. When geographical proximity is high, collaboration in scientific research development is apparently more likely to be successful, since a shorter physical distance is required in face-to-face interaction as a result of the tacit character of knowledge. High geographical proximity can compensate for the deficiencies in institutional differences during collaboration; that is, research collaboration concerning different types of organizations is more spatially localized because of shared interest in labor exchange, access to local funding, and mutual trust facilitated by informal contact and interactions. The closer potential collaborators are in geographical proximity, the more likely is informal communication among them, which could lead to a collaborative project.

Functional proximity is regarded as the operational nearness in terms of the ease and timing of one-on-one conversations (Monge and Kirtse, 1980). It reflects the capability of partners within a collaborative arrangement to organize face-to-face meetings in a matter of one working day (Moodysson and Jonsson, 2007). Functional proximity facilitates inter-firm relationships, by identifying easier communication and networking platforms that promote the emergence of a group or region-specific values (Belin and Monteil, 1999). Taking into account the quality of interactive channels and the shared areas within a geographical region provides partners with an opportunity to explore useable distances or passive contacts. Functional 
proximity changes over time, while geographical proximity is considered to be fixed. In Figure 2 , we propose a proximity model where nanotech companies could be affected by two major forms of proximity: geographical and functional.

Hla: The higher the geographical proximity to key partners; the greater the number of partners, the more centralized the governance mechanism, the stronger the value network and the longer the duration of collaborative partnerships in nanotech $R \& D$ Projects.

H1b: The higher the functional proximity to key partners; the greater the partner's size, the more centralized the governance mechanism, the stronger the value network and the shorter the duration of collaborative partnerships in nanotech $R \& D$ Projects.

Figure 2: A proposed model for proximity influence on collaboration

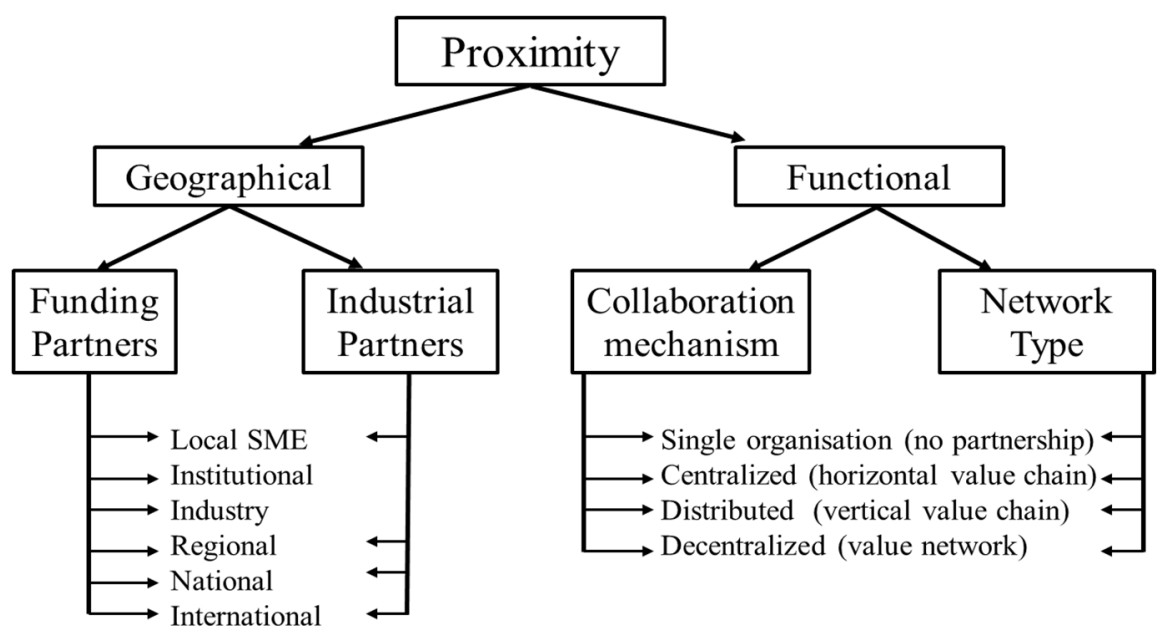

\subsection{Effects of legal origin on $R \& D$ collaboration}

In the literature, the modern inter-firm networks are highlighted as hybrid arrangements, which are typically comprised of suppliers, customers, competitors, regulatory bodies, and financial institutions (Todeva and Knoke, 2005; Contractor and Lorange, 2002). The advent of globalization and the homogeneity of regulations in countries have created more opportunities for companies to collaborate internationally and increase their competitive advantage (Beers and Zand, 2014). As a way of facilitating collaborations around the globe, governments have provided resources and incentives to promote the rapid growth and dissemination of scientific knowledge, in order to encourage indigenous innovation, exploit research synergy, and enhance scientific excellence. The pathway to a contemporary global scientific community usually goes through a transitionary period of strong nationalistic identity in science and technology.

The main external threats to effective international collaboration in $R \& D$ projects are foreign language predicaments, dissimilar legal systems, regulatory barriers, and domestic cultural difficulties (Bjorkman et al., 2007). Regarding the legal dynamics that impact the level of collaboration in nanotech organizations, historically determined variances in the legal traditions of countries could help explain the differences in the collaborative size and efficiency of institutions within the global scientific community (Beck et al., 2003). We adopted the theory of law and finance initiated by La Porta et al. (1999), which stipulates that countries with English Common Law origin generally possess stronger shareholder and creditor 
protection than countries with French, German or Scandinavian Law origins (La Porta et al., 2008). In order words, countries that have the English Common Law better protect investors against expropriations due to the robustness of its legal system, which features the independence of the judiciary and enables reduction of agency problems resulting in higher dividend pay-outs (Djankov et al., 2008). Superior alternative financial markets are found in countries with English Common Law origin, because shareholders' rights are better protected through the court system (Cumming, 2008). Building on this literature, we propose that a country's legal origin significantly influences the number of partners, the governance mechanism, strength and duration of R\&D collaborations.

H2a: If inter-firm R\&D projects are carried out within the jurisdiction of countries with French Civil Law origins; the number of partners reduces, the governance mechanism is centralized, the duration decreases and there is a weak value network in the collaborative partnerships of nanotech firms when compared with English Common Law Countries.

$H 2 b$ : If inter-firm $R \& D$ projects are carried out within the jurisdiction of countries with German Civil Law origins; the number of partners reduces, the governance mechanism is centralized, duration decreases and there is a weak value network in the collaborative partnerships of nanotech firms when compared with English Common Law Countries.

H2c: If inter-firm $R \& D$ projects are carried out within the jurisdiction of countries with Scandinavian Civil Law origins; the number of partners reduces, the governance mechanism is centralized, duration decreases and there is a weak value network in the collaborative partnerships of nanotech firms when compared with English Common Law Countries.

\subsection{Cultural dimensions in $R \& D$ collaboration}

As R\&D partnerships become more global, understanding national cultures becomes essential because it partly determines cooperative performance and affects the attainment of organizational goals (Franke et al. 1991). Culture is an established set of values that affects the way people think and behave within society, and which is passed down from generation to generation (Bosley, 1993). Globalization has facilitated the increase of trade among nations, and this has resulted in the convergence of cultures and collision of linguistic practices (Basu and Yoshida, 2013). Based on a cross-country study that analyzed certain cultural effects on business organizations, it could be argued that the attitudes of professionals can be derived from their religions and another cultural phenomena (Hofstede, 1983). As such, cultural variables explain the discrepancies in investor protection rights better than the legal traditions of countries, and key indicators such as language and religion affect financial market and technology development. Cultural differences affect the transfer proficiencies of companies in global inter-firm relationships through vital determinants such as social assimilation and prospective absorption capacity (Bjorkman et al. 2007; Licht et al. 2001).

The careful consideration of the cultural dynamics in inter-firm relations is a useful skill $21^{\text {st }}$ century managers need to possess to develop trust and enhance creativity in collaborative engagements (Chua, Morris, and Mor, 2012). Cross-cultural collaborations in high-tech industries experience lots of difficulties, which could be circumvented by choosing the right R\&D project to be subcontracted and by estimating its possible cooperative outcome (Krishna et al., 2004). There are four main cultural dimensions that act as differentiators to capture the complex nuances that describe culture (Hofstede, 1983). These cultural dimensions are: power distance, which is the extent to which the masses within a society accept that power is unevenly distributed; uncertainty avoidance, which is the degree to which tolerance for uncertainty and 
ambiguity is allowed or acceptable; individualism vs collectivism, which is the level to which people within a society are interdependent and are easily integrated into and committed to groups; and masculinity vs femininity, which is the degree to which a society is influenced by historically masculine or feminine values. However, we focused on the tolerance level of uncertainty and scale of female participation in science and technology fields when compared with their male counterparts. We, therefore, propose the following hypotheses:

H3a: The greater the degree of society's intolerance for ambiguous and uncertain business ventures, the lower the overall partnership size, the more centralized governance mechanism, the weaker the value network and the shorter the duration of collaborative partnerships in nanotech $R \& D$ projects.

H3b: The higher the degree to which masculine values prevail in society over feminine values, the greater the partnership's size, the more centralized the governance mechanism, the shorter the duration and the weaker the value network of collaborative partnerships in nanotech $R \& D$ projects.

\subsection{Economic growth and $R \& D$ collaboration}

Cultural values are economic performance determinants, which provide a useful explanation for the cross-national variance in economic growth of nations (Franke, Hofstede, and Bond, 1991). There is a positive relationship between the economic growth rate within a country and their level of human capital accumulation (Strulik, 2005). The rationale for R\&D cooperation and the size, structure, and time-frame is solely dependent on the net gains from the collaborative partnerships (Beers and Zand, 2014). The motives behind organizations undertaking inter-firm collaboration vary vastly and are dependent on firm-specific features and multiple environmental factors. Motives include: to increase their capacity to produce; decrease internal weaknesses and external threats; achieve greater control and organizational flexibility; realize market potential and obtain competitive advantage, leading to enhanced profitability and rapid growth (Todeva and Knoke, 2005).

Inter-firm cooperation has grown rapidly over the last 20 years because of the dynamic nature of the external environment of $\mathrm{R} \& \mathrm{D}$ projects. In other words, companies that have several collaborative arrangements with diverse partners are expected to have a more synergetic outcome in product development and receive complimentary information in the organizational learning. Cooperative engagements between high tech companies are used as market entry strategies into industries tightly controlled by the government to circumvent regulatory constraints during periods of economic growth, thereby strengthening their industry positions (Contractor and Lorange, 2002). In line with the literature we propose the following hypothesis:

H4: The higher the rate of economic growth within a country, the greater the partner's size, the more decentralized the governance mechanism, the stronger the value network and the longer the duration of collaborative partnerships in nanotech $R \& D$ projects.

\subsection{International demand for technologically-advanced products}

The main factors that determine the successful internationalization of commercial products are the harmonization of regulated markets and the technological sophistication of business ventures. These factors have different impacts on small- and medium-scale enterprises (SMEs) and large firms (Broocks and Van Biesebroeck, 2017). Most SMEs are required to be 
systematic in their product selection and strategic planning, in order to circumvent the inherent weaknesses of not having an adequate market niche and financial flexibility. In contrast, large firms have sufficient financial resources to ensure that their focus is on non-price marketing instruments (i.e., product, promotion, and place) that could enhance international demand for their new or existing products (Cavusgil and Kirpalani, 1993). A firm's export intensity is highly dependent on the quality of their products, because economic growth is significantly influenced by total factor productivity, which arises from the innovative performance of hightech firms (Curzi and Olper, 2012). Higher export performance is usually associated with efficient, innovative firms that can create top-quality products at reasonably high prices for effective distribution to distant markets (Fajgelbaum, Grossman and Helpman, 2011). Globalisation influences the scale and scope of multi-product firms via competition and demand effects (Eckel and Neary, 2010).

H5: The higher the export demand for a country's technologically advanced products, the greater the number of partners, the more centralized the governance mechanism, the shorter the duration and the stronger the value network of collaborative partnerships in nanotech $R \& D$ projects.

\subsection{Organizational size and $R \& D$ collaboration}

The international collaborative networks are very dynamic, rapidly increasing, and highly influential. External networking compliments the internal R\&D activities of SMEs when economies of scale and/or integration of diverse skills and technologies could be achieved (Mancinelli and Mazzanti, 2009). Compared with large companies, SMEs are significantly unable to establish the most suitable external network of partners for collaboration (Rothwell and Dodgson, 1991). As SMEs have smaller external relations than large companies, they are more confined to their local region because of the need to have direct interactions in tacit knowledge exchange. Large firms are far more likely to have a cooperative relationship with the vertical partners (such as universities, research institutes, and training centers) in their supply chain than SMEs. However, technology-driven SMEs are uniquely different in this regard.

The inability of SMEs to engage in vast cooperative partnerships, outside their business relations, is due to the low financial resources available and the small number of employees capable of initiating and preserving network links (Kaufmann and Todtling, 2002). As far as external network relations are concerned, SMEs are focused more on developing regional partnerships than are large companies. Multi-national corporations (MNCs) have a competitive advantage, resulting from their superior ability to transfer and combine competencies across geographically dispersed entities. The global exploitation of science and technology by MNCs better describes the much greater rate of growth of international patent applications than the growth rate of national patent applications (Todeva and Knoke, 2005; Bjorkman et al. 2007). However, it is extremely problematic for MNCs to pursue speculative opportunities and/or mitigate unestablished threats posed by disruptive innovations, due to their cultural and structural impediments (Lindsay and Hopkins, 2010).

H6: The larger the organizational size of nanotech firms, the lesser the number of partners, the more centralized the governance mechanism, the shorter the duration and the stronger the value network of $R \& D$ collaborative projects. 


\subsection{VC Fund Manager's Participation in $R \& D$ projects}

Venture capital (VC) is an independent, professionally managed, dedicated pool of capital that focuses on equity or equity-related investments in privately held, high-growth companies (Gompers and Lerner, 2001). VC funds are a collective investment scheme used in making investments in various portfolio companies. A large portion of the global VC industry operations can be attributed to the entrepreneurial spirit prevalent in the United States. Also, the access OECD countries have to efficient capital markets, skilled workforces, effective intellectual property protection and sophisticated research facilities enhance their VC activities and performance (Djankov et al., 2008). VC plays a vital role in building a vibrant private sector by channeling funds to young entrepreneurs, who are unable to access seed capital from banks due to their reluctance to finance unproven business ventures and industries (Ewing, 2004). VC investments are essential to SMEs due to: knowledge transfer through partnerships; high liquidity, which facilitates sustained economic growth; employment generation and youth empowerment; and the identification and funding of winning firms and ideas.

The internationalization of the VC industry in the 1990s has allowed for a vast and steady increase in cross-border VC investments around the world, such that foreign VC participation in local portfolio companies now accounts for one-third of global VC activities (Schertler and Tykvova, 2012). One of the effects of globalization has been the facilitation of cross-border VC activities, due to the relative ease of labor restrictions, capital controls and banking regulations among developed countries and emerging markets (Wang and Wang, 2011). VC fund managers participate in the strategic management of portfolio companies they have invested into, to monitor and influence the activities of the board of directors. As VC-funded companies usually reach maturity within 5-7 years, divestments become essential due to the need to ensure the liquidity of VC funds, distribute returns, evaluate performance and/or reallocate entrepreneurial finance.

H7: The participation of VC fund managers in nanotech $R \& D$ projects increases the number of partners, centralizes the governance mechanisms, shortens the duration and strengthens the value network of collaborative partnerships.

\subsection{Innovative capacity and $R \& D$ collaboration}

Collaboration in scientific communities provides several benefits, such as: the transfer of knowledge, skills, and techniques; the cross-fertilization of concepts and ideas; the provision of intellectual companionship; and increasing the prominence of research work. The use of intellectual asset strategies in preserving opportunities for, or avoiding threats from, disruptive innovations is critical to the survival of R\&D organizations, because of the most likely loss in their market position (Lindsay and Hopkins, 2010). Patents and other intellectual property should be used to meet the needs of low-end and prospective customers. In university-industry partnerships, there are valid financial considerations for supplementing patents with publications. The fear of misappropriation and the cost of knowledge transfer impede the formation of inter-firm relationships, due to the knowledge intensity of firms and the stickiness in transferring vital information among their supply chain (Contractor and Lorange, 2002). The innovative capacity of a high-tech organization is their ability to develop and commercialize innovative ideas, products, and services over a sustained period of time (Guan and Ma, 2003). It represents R\&D firm management's effectiveness in converting scientific and technical productivities into profitable, innovative marketable products, which could drive radical and/or disruptive technologies into the marketplace to dominate industries (Koc and Ceylan, 2007). 
H8: The greater the innovative capacity of nanotech firms involved in $R \& D$ projects, the lower the number of partners, the more centralized the governance mechanism, the shorter the duration and the stronger the value network of their collaborative partnerships.

\section{Research Design}

In this study, we employed a mixed research method to critically examine the external complexities that affect the dimensions of collaboration in nanotech firms. Figure 3 shows the research outline of this study. The conceptual framework is based on theories of inter-firm relations, proximities in collaborative partnerships, national culture influences on interorganizational behavior, legal origin as a determinant of financial development, and the international demand for technologically advanced products. These theories provide the basis for constructing and testing our hypotheses to produce empirical results on the external factors that affect the dimensions of inter-firm collaborations in nanotech $R \& D$ projects across Europe.

Figure 3: Research outline of the study

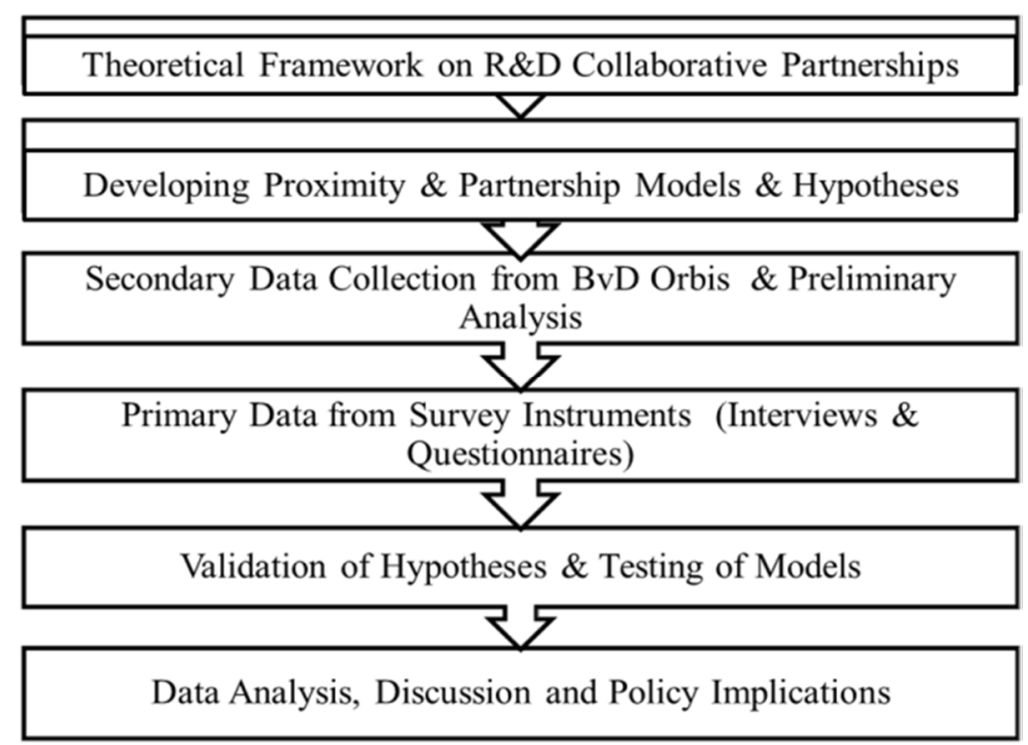

\subsection{Data}

The collaborative $\mathrm{R} \& \mathrm{D}$ projects in our data sample involve various characteristics of nanoscience and nanotechnologies, such as the development of nanotubes and nanowires for electrical and biological consumption, plus the use of nanoparticles and the construction of nano-instruments for manufacturing and communication purposes. These nanotech $R \& D$ projects include but are not limited to: electrical discharge machining, multi-component injection molding, electroforming, powder injection molding, nanoimprinting, X-ray lithography, selective laser sintering, chemical vapor deposition, nanometer-scale measurement and future tooling technology.

We adopted a mixed research method where both quantitative and qualitative data were used to enrich the process of data collection and analysis. We collected secondary data on the organizational size, some patents, VC participation and industry and academic links to nanotech R\&D projects from the Orbis database of Bureau van Dijk (BvD). We also collected, 
from the World Bank database, the annual GDP growth rates and export demand for high-tech products for the relevant countries during the period of the nanotech R\&D collaborations. Due to insufficient quantitative data on the collaborative dynamics of nanotech firms, we used survey instruments to generate interview and questionnaire data on geographical and functional proximity, governance mechanism, strength and duration of the partnership. The responses were then coded into ordinal observations. We conducted 30 interviews with top executives of nanotech firms and provided 97 questionnaires to senior administrators of nanotech $R \& D$ projects across 12 European countries.

Finally, we incorporated the legal origin index developed by La Porta et al., (1999); and subsequently modified by Beck et al., (2003); Spamann, (2009); and Cooray, (2011). The legal origins index represents the political structure and legal adaptability of countries where collaborative partnerships in nanotech $\mathrm{R} \& \mathrm{D}$ projects took place. Therefore, our measurement for estimating the legal dynamic affecting the dimensions of nanotech $R \& D$ collaborations was based on the tenure of Supreme Court judges, judicial independence, and legal justification. Similarly, we adopted the national cultural dimension indexes proposed by Hofstede (1983; 1994) for all the collaborative partnerships in nanotech $R \& D$ projects in our dataset, using uncertainty avoidance and masculinity vs. femininity indexes to provide measures of societal attitude towards ambiguity and the level of public intolerance for feminine values. We then carried out ordinary least square (OLS) regressions to analyze our data and provide empirical tests of our research hypotheses.

\subsection{Dependent variable(s)}

The key variables of interest in our study are four features of inter-firm relations, namely: partnership size; governance mechanism; the strength of value network, and; time-frame to secure a patent or develop a new product during collaboration in nanotech R\&D projects. The main dependent or response variable in our study is the size of the cooperative partnerships; the number of total partners in a distinct nanotech $R \& D$ project. We also developed three other dependent variables to consider the other dimensions of collaboration in nanotech $R \& D$ projects. The second dependent variable is the type of organizational structure in the collaborative partnerships of nanotech $R \& D$ projects. This ranges from level 1 to 3 , i.e. from centralized to distributive and then decentralized governance mechanisms. The third response variable is the time frame (i.e., the duration) of $R \& D$ collaboration, which we group into short-, medium- and long-term periods. The final dependent variable is the ordinal scale of the strength of value network in nanotech R\&D projects. This is ranked from 1 to 6 and contains three groupings of weak, medium and strong level of interactions with suppliers, consumers, regulators, legal bodies, open innovations and academic institutions.

\subsection{Independent variable(s)}

The independent variables remained, for the most part, the same in the four models used in our study. They were employed to determine the factors that influence the dimensions of collaborative partnerships in nanotech $\mathrm{R} \& \mathrm{D}$ projects, based on our theoretical framework. The variables that help explain the variations in the dimensions of collaborative partnerships in nanotech R\&D projects include: geographical \& functional proximity; legal origins (dummies for English Common Law and French, German and Scandinavian Civil Law); national cultural dimension indexes (Uncertainty Avoidance \& Masculinity vs Femininity); average annual GDP growth rate, and; export demand for high-tech products during the period of the R\&D collaborations. Table 1 lists and describes most of the key variables and their expected relationship with the observed variable in model 1. 
Table 1: Key Variables, Expected Relationships, and Brief Description

\begin{tabular}{|c|c|c|c|}
\hline S/N & Variables & Effects & Description \\
\hline 1 & $\begin{array}{l}\text { Size of } \\
\text { Partnership }\end{array}$ & + & $\begin{array}{l}\text { The total number of partners in a collaborative } \mathrm{R} \& \mathrm{D} \\
\text { project. }\end{array}$ \\
\hline 2 & $\begin{array}{l}\text { Governance } \\
\text { Mechanism }\end{array}$ & - & $\begin{array}{l}\text { The type of organizational structure (coded 1-3 from } \\
\text { centralized to distributive to decentralized). }\end{array}$ \\
\hline 3 & $\begin{array}{l}\text { Innovative } \\
\text { Capacity }\end{array}$ & - & $\begin{array}{l}\text { The number of patents held before the start of the } \\
\text { nanotech R\&D projects. }\end{array}$ \\
\hline 4 & $\begin{array}{l}\text { Geographical } \\
\text { Proximity }\end{array}$ & + & $\begin{array}{l}\text { The geographical nearness to industrial partners (coded } \\
1-4 \text { for international, national, regional, \& local } \\
\text { closeness. }\end{array}$ \\
\hline 5 & $\begin{array}{l}\text { Legal Origin } \\
\text { Indexes }\end{array}$ & - & $\begin{array}{l}\text { Country Indexes of French, German and Scandinavian } \\
\text { Civil Law as well as English Common Law origins. }\end{array}$ \\
\hline 6 & $\begin{array}{l}\text { Venture Capital } \\
\text { Participation }\end{array}$ & + & $\begin{array}{l}\text { A dummy variable for VC fund managers' participation } \\
\text { in nanotech R\&D projects (coded } 1 \text { and otherwise } 0 \text { ). }\end{array}$ \\
\hline 7 & $\begin{array}{l}\text { Masculinity(vs) } \\
\text { Femininity }\end{array}$ & + & $\begin{array}{l}\text { Cultural index of societal attitude towards feminine } \\
\text { values. }\end{array}$ \\
\hline 8 & $\begin{array}{l}\text { Uncertainty } \\
\text { Avoidance }\end{array}$ & - & $\begin{array}{l}\text { Cultural index of tolerance for uncertainty and } \\
\text { ambiguity. }\end{array}$ \\
\hline 9 & $\begin{array}{l}\text { Organizational } \\
\text { Size }\end{array}$ & - & $\begin{array}{l}\text { Dummy variable (1) for large firms and (0) for SMEs } \\
\text { based on the total assets of nanotech R\&D firms. }\end{array}$ \\
\hline 10 & $\begin{array}{l}\text { Technological } \\
\text { Advancement }\end{array}$ & + & $\begin{array}{l}\text { The country's average export demand for high-tech } \\
\text { products in the period of R\&D collaboration. }\end{array}$ \\
\hline 11 & $\begin{array}{l}\text { Academic } \\
\text { Affiliation }\end{array}$ & + & $\begin{array}{l}\text { A dummy variable: (1) for academic involvement in } \\
\text { nanotech R\&D projects and (0) for otherwise. }\end{array}$ \\
\hline 12 & $\begin{array}{l}\text { Economic } \\
\text { Growth }\end{array}$ & + & $\begin{array}{l}\text { The average rate of annual GDP growth during the } \\
\text { period of R\&D collaboration. }\end{array}$ \\
\hline 13 & $\begin{array}{l}\text { Functional } \\
\text { Proximity }\end{array}$ & + & $\begin{array}{l}\text { Functional nearness to value networks, i.e. (1-4) no } \\
\text { partnership, suppliers, customers and both. }\end{array}$ \\
\hline 14 & $\begin{array}{l}\text { Biotechnology } \\
\text { Industry }\end{array}$ & + & $\begin{array}{l}\text { A dummy variable, (1) for nano-biotechnology type of } \\
\text { R\&D projects and (0) for otherwise. }\end{array}$ \\
\hline
\end{tabular}

Source: Author compilation of Orbis Database, World Bank Database, La Porta et al. (1999), and Hofstede (1994) Indexes.

\subsection{Control variable(s)}

We control for the organizational size of the nanotech firms based on the total assets of nanotech R\&D firms. Also, we control for academic affiliations and venture capital participation, as well as the existing innovative capacity held by the nanotech organizations in $R \& D$ collaboration. The number of patents held by the $R \& D$ collaborative partnerships is used as a proxy for innovative capacity. Controlling these variables help us better understand the effects of our independent variables on the observed variable.

\subsection{Multiple regression models (OLS)}

Since collaborative partnership can be observed in several ways, we developed two multiple regression models aimed at incorporating the different forms of collaboration in nanotech $R \& D$ projects. We adopted two different attributes of collaborative partnerships regarding the partner's size and governance mechanism of nanotech R\&D projects. We used multiple linear regression models to derive OLS estimates that minimize the squared residuals of best fit. We specify our initial regression models for this research study in equation 1 below: 


$$
\gamma_{i}=\beta_{0}+\beta_{1} X_{i 1}+\beta_{2} X_{i 2}+\ldots+\beta_{k} X_{i k}+\varepsilon_{i} \quad i=1,2 \ldots n
$$

Where $\gamma$ is the response variable for the $\mathrm{i}^{\text {th }}$ observation, which is the size of collaborative partnerships in all $97 \mathrm{R} \& \mathrm{D}$ projects; $\beta_{0}$ is the constant or intercept that depicts the relationship that exists without the inputs of our explanatory variables. $\beta_{1}$ to $\beta_{\mathrm{k}}$ are the parameters and $\mathrm{X}_{1}$ to $\mathrm{X}_{\mathrm{k}}$ are the coefficients, while $\varepsilon$ is the error term that describes the random element of the linear relationships between explanatory and response variables.

\subsection{Logistic regression models}

We formulated two logistic regression models that estimate the likelihood of our binary dependent output, based on several predictor variables. These are generalized linear models, which were used to analyze the variations in our dichotomous response variable about the independent variable. We specify our logistic regression models for this research study in equation 2 below:

$$
\log \left(\frac{p(y=1)}{1-p}\right)=\boldsymbol{\beta}_{\mathbf{o}}+\boldsymbol{\beta}_{1} * \boldsymbol{x}_{i 1}+\boldsymbol{\beta}_{2} * \boldsymbol{x}_{\boldsymbol{i} 2}+\cdots+\boldsymbol{\beta}_{\boldsymbol{k}} * \boldsymbol{x}_{\boldsymbol{i k}} \quad i=1 \ldots k
$$

Where logit $(\mathrm{p} / 1-\mathrm{p})$ is the probability of the presence of long-term duration or strong value network and is transformed into the logged odds for the $i^{\text {th }}$ observation as the duration and strength of collaborative partnerships in all $30 \mathrm{R} \& \mathrm{D}$ organizations. $\mathrm{y}$ is a binary response variable. $\mathrm{y}_{i}=1$ if the duration is long-term or strength is strong; $\mathrm{y}_{\mathrm{i}}=0$ if otherwise. $\mathrm{x}=\left(\mathrm{x}_{1}\right.$, $\left.\mathrm{x}_{2}, \ldots, \mathrm{x}_{\mathrm{k}}\right)$ is the set of explanatory variables. $\mathrm{x}_{\mathrm{i}}$ is the observed value of the explanatory variables for observation $i$.

\section{Results}

In this section, the findings of our regression models are presented. Descriptive statistics and the correlation matrix are presented in Table 2, and the multiple (models 1\&2) and logistic (models $3 \& 4$ ) regression models are presented in Table 3.

\subsection{Descriptive statistics}

Table 2 provides the mean, standard deviation and correlation matrix of our study. Of particular importance are the means of GDP growth and innovative capacity, which are (70.66667) \& (632.9667) respectively.

\subsection{Inferential statistics}

In model 1, we concentrated on the factors that influence the sizes of partnerships among nanotech $R \& D$ organizations. We used the total number of partners involved in the $R \& D$ projects that lead to new product development. We find that a high geographical closeness between nanotech $R \& D$ collaborative partners positively influences the total amount of partners, despite the limited nanotech specialists and clusters within a local region. Effective R\&D collaborations among nanotech firms are dependent on highly skilled scientists who operate on very complex and expensive scientific instruments that require a high level of geographical proximity to achieve innovative productivity within a specified period of time. Also, we find that a high functional closeness in inter-firm relations positively influences the number of partners in nanotech R\&D projects, due to the extra effort employed by senior administrators to establish useful forms of interaction, which reduces the communication distance. 
Table 2: Descriptive statistics and correlation matrix

\begin{tabular}{|c|c|c|c|c|c|c|c|c|c|c|c|c|c|c|c|c|}
\hline & Mean & Std. Dev & 1 & 2 & 3 & 4 & 5 & 6 & 7 & 8 & 9 & 10 & 11 & 12 & 13 & 14 \\
\hline 1 Organisational Size & 2.333333 & 0.6064784 & 1 & & & & & & & & & & & & & \\
\hline 2 GDP Growth & 70.66667 & 14.98121 & 0.3901 & 1 & & & & & & & & & & & & \\
\hline 3 Uncertainty Avoidance & 39.7 & 12.99907 & -0.1774 & -0.3416 & 1 & & & & & & & & & & & \\
\hline 4 Masculinity vs Femininity & 55.4 & 22.82255 & -0.1656 & 0.0364 & -0.0301 & 1 & & & & & & & & & & \\
\hline 5 French Civil Law & 59.26667 & 21.86941 & -0.4959 & -0.6571 & 0.7624 & 0.3658 & 1 & & & & & & & & & \\
\hline 6 German Civil Law & 1481.611 & 4448.208 & 0.1718 & -0.0589 & -0.1811 & 0.1459 & 0.0038 & 1 & & & & & & & & \\
\hline 7 Scandinavian Civil Law & 5.733333 & 2.531639 & -0.4836 & -0.0291 & -0.1426 & 0.3612 & 0.0404 & -0.0424 & 1 & & & & & & & \\
\hline 8 Technological Advancement & 0.5341852 & 1.445741 & -0.3014 & -0.0864 & 0.6226 & -0.1388 & 0.3449 & -0.1334 & -0.0196 & 1 & & & & & & \\
\hline 9 Innovative Capacity & 632.9667 & 2223.098 & 0.2496 & 0.0516 & -0.193 & 0.0938 & -0.0761 & 0.9531 & -0.0411 & -0.1487 & $7 \quad 1$ & & & & & \\
\hline 10 Geographical Proximity & 3.7 & 0.4660916 & -0.1741 & -0.1615 & 0.11 & -0.1649 & 0.1989 & 0.1805 & -0.2137 & -0.156 & 0.0998 & 1 & & & & \\
\hline 11 Functional Proximity & 3.333333 & 0.8022956 & 0.3237 & -0.18 & 0.0006 & 0.1697 & 0.0143 & 0.2243 & 0.2332 & -0.0524 & 40.1996 & $6-0.2425$ & 1 & & & \\
\hline 12 Venture Capital Participation & 0.1666667 & 0.379049 & 0.1741 & 0.4543 & -0.2957 & 0.0195 & -0.3838 & 0.4675 & 0 & -0.2052 & 20.5093 & -0.2 & -0.0808 & 1 & & \\
\hline 13 Academic Affiliation & 0.7 & 0.4660916 & 0.0316 & 0.1448 & 0.2267 & 0.2779 & 0.1124 & -0.3605 & -0.0388 & 0.1135 & -0.304 & 0.0605 & 0.0147 & -0.3026 & 1 & \\
\hline 14 Biotechnology Industry & 2.239005 & 9.544838 & 0.1933 & 0.2933 & -0.1661 & 0.099 & -0.2663 & 0.0145 & -0.0939 & -0.0833 & 30.1481 & -0.2475 & -0.1554 & 0.3088 & 0.1342 & 1 \\
\hline
\end{tabular}

Furthermore, our results show that, in countries with a high level of intolerance for ambiguous commercial ventures, there is a low number of total partners in nanotech R\&D projects. Likewise, where the national culture of countries is that masculine values heavily dominate over feminine ones, there are usually fewer partners involved in nanotech R\&D projects. Regulatory barriers, as well as low female participation in science and technology, are possible reasons for these cultural effects on the size of collaborative partnerships in nanotech $R \& D$ projects. Also, our results show that the economic expansion of a country enhances the sizes of collaborative partnerships in nanotech $R \& D$ projects, due to the additional sources of funds available for R\&D expenditure. As expected, a high GDP growth positively influences the number of total partners in collaborative nanotech R\&D projects. Similarly, an active VC fund manager's participation in the strategic activities of nanotech firms significantly adds to the sizes of collaborative partnerships; we believe this is in order to monitor and supervise the $\mathrm{R} \& \mathrm{D}$ projects so that innovative performance is attained as early as possible.

Nevertheless, there was weak support for some findings, notably the idea that countries with a legal origin in French Civil Law thwart more collaborative partnerships in nanotech R\&D projects, compared with English Common Law, as a result of their rigid labor laws (La Porta et al., 1999). Larger nanotech firms are capable of collaborating with more partners in an R\&D project, compared with their SME counterparts, because they have greater financial resources and better human capital (Zheng et al., 2014). Also, we find that countries with high export demand for technologically advanced products and services tend to have a large number of partners in nanotech R\&D collaborations. With low significance level, we find that the innovative capacity of nanotech R\&D firms negatively affects the sizes of their collaborative partnerships, as previous scientific productivity makes high-tech firms hoard secret commercial information for competitive advantages.

Table 3: Multiple \& Logistic Regression Coefficients

\begin{tabular}{|llll|}
\hline$\underline{(\text { Model 1) }}$ & $\underline{(\text { Model 2) }}$ & $\underline{(\text { Model 3) }}$ & $\underline{(\text { Model 4) }}$
\end{tabular}




\begin{tabular}{|c|c|c|c|c|}
\hline & $\frac{\text { Size of Total }}{\underline{\text { Partnership }}}$ & $\frac{\text { Governance }}{\text { Mechanism }}$ & $\begin{array}{c}\text { Duration of } \\
\text { Collaboration }\end{array}$ & $\begin{array}{l}\text { Strength of } \\
\text { Partnership }\end{array}$ \\
\hline Geographical Proximity & $\begin{array}{c}0.155^{* * *} \\
(6.02)\end{array}$ & $\begin{array}{l}-0.135 \\
(-1.63)\end{array}$ & $\begin{array}{c}-0.851^{*} \\
(-5.44)\end{array}$ & $\begin{array}{c}0.0000981^{* *} \\
(6.30)\end{array}$ \\
\hline Functional Proximity & $\begin{array}{c}0.394 * * \\
(7.74)\end{array}$ & $\begin{array}{c}-0.0465^{*} \\
(-3.52)\end{array}$ & $\begin{array}{c}0.212 * \\
(4.99)\end{array}$ & $\begin{array}{c}0.512^{*} \\
(5.24)\end{array}$ \\
\hline French Civil Law & $\begin{array}{c}-0.0249^{*} \\
(-3.28)\end{array}$ & $\begin{array}{c}-0.103^{* * * *} \\
(-8.96)\end{array}$ & $\begin{array}{c}-0.000169 \\
(-1.67)\end{array}$ & $\begin{array}{c}-0.00816^{* *} \\
(-6.19)\end{array}$ \\
\hline German Civil Law & $\begin{array}{c}-0.0676 \\
(-1.36)\end{array}$ & $\begin{array}{c}-0.603^{* *} \\
(-3.86)\end{array}$ & $\begin{array}{l}-0.116 \\
(-1.22)\end{array}$ & $\begin{array}{l}-0.433 \\
(-2.17)\end{array}$ \\
\hline Scandinavian Civil Law & $\begin{array}{l}-0.0244 \\
(-2.10)\end{array}$ & $\begin{array}{l}-0.0701 \\
(-1.39)\end{array}$ & $\begin{array}{c}-0.240 * * \\
(-6.52)\end{array}$ & $\begin{array}{l}-0.108 \\
(-1.92)\end{array}$ \\
\hline Uncertainty Avoidance & $\begin{array}{c}-0.0201 * * \\
(-5.53)\end{array}$ & $\begin{array}{c}-0.0474 * * * \\
(-4.86)\end{array}$ & $\begin{array}{c}-0.157 * * * \\
(-14.82)\end{array}$ & $\begin{array}{c}-0.276^{* *} \\
(-8.29)\end{array}$ \\
\hline Masculinity vs Femininity & $\begin{array}{c}-0.0542 * * * \\
(-8.10)\end{array}$ & $\begin{array}{c}-0.0639 * * * \\
(-4.76)\end{array}$ & $\begin{array}{c}-0.364 * * * \\
(-16.15)\end{array}$ & $\begin{array}{c}-0.545^{* *} \\
(-8.41)\end{array}$ \\
\hline GDP Growth & $\begin{array}{c}0.0692 * * * \\
(8.89)\end{array}$ & $\begin{array}{c}0.0674 * \\
(3.08)\end{array}$ & $\begin{array}{c}0.402 * * * \\
(15.76)\end{array}$ & $\begin{array}{c}0.584^{* * *} \\
(8.48)\end{array}$ \\
\hline Organizational Size & $\begin{array}{c}-0.0189 * \\
(-2.92)\end{array}$ & $\begin{array}{c}-0.133 * * \\
(-3.52)\end{array}$ & $\begin{array}{c}-0.353^{* * *} \\
(-14.71)\end{array}$ & $\begin{array}{c}0.628 * * \\
(8.67)\end{array}$ \\
\hline VC Participation & $\begin{array}{c}0.398^{* *} \\
(4.21)\end{array}$ & $\begin{array}{c}-0.00825 \\
(-2.25)\end{array}$ & $\begin{array}{c}-0.00189 * \\
(-2.69)\end{array}$ & $\begin{array}{l}0.511 \\
(2.05)\end{array}$ \\
\hline Innovative Capacity & $\begin{array}{c}-0.000131^{*} \\
(-2.83)\end{array}$ & $\begin{array}{c}-0.000163^{* *} \\
(-4.22)\end{array}$ & $\begin{array}{c}-0.000526^{*} \\
(-2.59)\end{array}$ & $\begin{array}{c}0.00863 * * \\
(6.47)\end{array}$ \\
\hline Technological Advancement & $\begin{array}{l}0.248 * \\
(3.13)\end{array}$ & $\begin{array}{c}0.0948^{*} \\
(2.57)\end{array}$ & $\begin{array}{c}-0.0713^{*} \\
(-3.46)\end{array}$ & $\begin{array}{c}0.171 * * \\
(3.66)\end{array}$ \\
\hline Academic Affiliation & $\begin{array}{l}2.065^{*} \\
(2.95)\end{array}$ & $\begin{array}{c}0.635^{* *} \\
(4.02)\end{array}$ & & $\begin{array}{c}0.822 * \\
(5.28)\end{array}$ \\
\hline Biotechnology Industry & $\begin{array}{l}0.0637 \\
(2.00)\end{array}$ & $\begin{array}{c}0.303^{*} \\
(2.44)\end{array}$ & $\begin{array}{c}0.738^{* *} \\
(11.38)\end{array}$ & $\begin{array}{c}0.110 * * \\
(4.40)\end{array}$ \\
\hline ICT Industry & $\begin{array}{c}-0.0000373 \\
(-1.28)\end{array}$ & $\begin{array}{c}0.0367^{*} \\
(2.45)\end{array}$ & $\begin{array}{c}-0.0510^{* *} \\
(-7.62)\end{array}$ & $\begin{array}{c}0.0165 \\
(2.09)\end{array}$ \\
\hline Constant & $\begin{array}{c}4.393 * * * \\
(8.04)\end{array}$ & $\begin{array}{c}6.349 * * * \\
(6.80)\end{array}$ & $\begin{array}{c}32.25 * * * \\
(18.96)\end{array}$ & $\begin{array}{c}14.29 * * \\
(5.02)\end{array}$ \\
\hline No. of Observations & 97 & 97 & 30 & 30 \\
\hline Adjusted R2 & 0.85 & 0.80 & & \\
\hline Pseudo R2 & & & 0.89 & 0.87 \\
\hline
\end{tabular}

Our multiple and logistic regression coefficients (p-value) in the 4 models. The significance is ***1\%, **5\% \&*10\%.

In model 2, we focused on the factors that affect the types of organizational structure in interfirm collaborations of nanotech $R \& D$ projects across Europe. The main variable of interest is the kind of governance mechanism among partners in the R\&D projects. We looked intensely at the method of control among collaborative partners (whether it was a decentralized, distributed or centralized system of governance) and how it was affected by external factors 
such as legal origin, cultural dimensions and geographical proximity of nanotech firms, while controlling for organizational size, academic affiliation and innovative capacity. Our results show that legal origins significantly affect the governance mechanisms of collaborative partnerships in nanotech $R \& D$ projects. We find that nanotech firms that carry out their collaborative R\&D projects in countries with French and German Civil Law origins have centralized governance mechanisms, compared with English Common Law origin, because of the need to tightly control the activities of their partners to adhere to stringent regulatory policies.

Moreover, our results show that a country's cultural attitudes concerning uncertainty and feminine values affect the way nanotech $R \& D$ projects are managed. A high intolerance for ambiguous nanotech $R \& D$ projects within a society brings about centralized governance mechanisms, which lead to less innovative outcomes. Likewise, a dominant masculine culture within a society means that nanotech $R \& D$ projects tend to have centralized governance mechanisms that seek to achieve organizational objectives at the earliest possible time frame. Also, our results show that economic growth has a positive but weak impact on the governance mechanisms in collaborative partnerships of nanotech R\&D projects. Here we argue that the availability of economic opportunities during boom times creates a tendency towards decentralized or distributed systems of governance, which foster innovative engagement among collaborative partnerships. Similarly, the export demand for high-tech products represents a form of a nation's technological advancement: we find that, when it is high, it negatively affects the nature of the governance mechanisms employed by collaborative partnerships in nanotech $R \& D$ projects. We also find that a high innovative capacity and a large organizational size both facilitate centralized governance mechanisms in the collaborative partnerships of nanotech R\&D firms.

In model 3, we focused on the external factors that affect the durations of collaborative partnerships with nanotech R\&D organizations. Model 3 specifies the determinants of the period in which $R \& D$ cooperative engagements take place in only two periods, i.e. short- and medium-term versus long-term durations. Our results show that the likelihood of a long-term inter-firm relationship in nanotech $\mathrm{R} \& \mathrm{D}$ projects is reliant on the legal origins, cultural values, economic growth, organizational size and industry affiliations. Specifically, nanotech R\&D projects that are carried out in countries with an origin in Scandinavian Civil Law are more likely to be shorter duration, compared with their counterparts in English Common Law countries. Also, a high intolerance for ambiguous R\&D projects most likely reduces the duration of collaborative partnerships among nanotech firms. Likewise, a dominant masculine culture within a society increases the likelihood of short-term R\&D collaboration. Also, a high GDP growth rate is more likely to have a positive effect on the time spent in nanotech collaborations, as funding from $\mathrm{R} \& \mathrm{D}$ expenditure increases. As funding prospects are enhanced during a period of economic expansion, underperforming nanotech $\mathrm{R} \& \mathrm{D}$ projects could continue to receive the financial resources needed to fund such operations, and thereby extend the duration and increase the manpower available to ensure that a new product is developed and/or patent secured. Finally, we find that organizational size and industry affiliations influence the duration of R\&D collaborations among nanotech firms. The larger the organizational size, the more likely there were short- and medium-term R\&D collaborations. Finally, nanotech $R \& D$ projects with biotechnology firms take longer, while those with information and communication companies are more likely to take a shorter time frame.

In model 4, we focused on external determinants of the strengths of value networks in interfirm collaborative partnerships of nanotech $R \& D$ projects. We find that geographical 
proximity, legal origins, cultural values, economic growth, organizational size, innovative capacity, technology advancement and industry affiliations all significantly influence the strengths of value networks in nanotech collaborative partnerships. Specifically, we find that a high geographical proximity (not strongly but significantly) is likely to positively affect the strengths of the value networks of nanotech $R \& D$ projects. Also, countries with French Civil Law origins are likely to weaken the value networks of nanotech $R \& D$ projects, compared with those with legal origins in English Common Law countries. Likewise, countries where uncertainty avoidance is high, and where masculine values prevail over feminine values, are more likely to have a weaker value network. Also, a high economic growth rate and a high export demand for technologically advanced products are likely to have a positive impact on the strengths of value networks in nanotech R\&D projects. Finally, a high innovative capacity, large nanotech organization, and affiliation to biotechnology industry are likely to have a positive effect on the strengths of value networks in $R \& D$ collaborations.

\section{Discussion and Implications}

In this section, we identify possible opportunities and challenges for policy-makers and organizational strategists to exploit or guard against, with the objective of enhancing various dimensions of collaborative partnerships within the nanotech $R \& D$ projects.

\subsection{Legal origins}

Countries with French Civil Law Origins have a less rigorous legal system (La Porta et al., 1999). Nanotechnology is an emerging technology that has few laws regulating its industry. The French and German legal systems provide a lesser degree of flexibility for securing patents and higher level of predictability for estimating litigation outcomes. This makes it less appealing to nanotech $R \& D$ collaborative partnerships, because there are lots of regulations that either restrict the nature and scale of research exploration and commercial exploitation or that could pose a huge threat and raise the possibility of large losses - unlike the English legal system, where there is an inherent rule to have minimum standards of care.

The impact of nanoscience and nanotechnologies has been keenly highlighted by prominent individuals (Charles, 2004), interest groups (Royal Society and Royal Academy of Engineering) and even movies ("grey goo"), so as to promote thorough risk assessments and further regulatory activities, and ensure that a high level of ethical standards are employed during commercial development. These assurances have significantly reduced the British public's concerns about the ambiguities in nanoscience and nanotechnology. Therefore, it is imperative for nanotech firms in countries with an English Common Law origin to take into consideration the additional cost required to make risk assessments about their R\&D projects publicly available, in order to enhance public awareness and reduce the general intolerance for uncertainties associated with nanotechnology.

\subsection{Proximity}

Despite the advancements in information and communication technologies (ICT), as well as the free movement of capital and labor across Europe, geographical and functional closeness still matters greatly in determining the size, command chain, strength and duration of collaborative partnerships in nanotech $R \& D$ projects. Spatial nearness among scientists negatively influences the partnership size, but positively affects the organizational structure of collaborative partnerships in nanotech R\&D projects (Knoben and Oerlemans, (2006). 
Nanotechnology is an interdisciplinary field that requires a great deal of physical closeness among R\&D partners, who use very complex instruments to develop innovative products and services through a decentralized system of governance that minimizes contingency risks (Steinmo and Rasmussen, 2016). The lack of a concentration of nanotechnology experts within a local scientific community in the past has created a need for international collaborations with a distributive organizational structure, in spite of the drawbacks from their geographical closeness (Kabo et al., 2014).

Functional proximity relates to the nearness of partners regarding their basic operations and areas of specialty during the R\&D collaborations. The quality of the value network is strengthened when there was a substantial division of labor and clearly defined roles, which enabled partners to uniquely contribute to the nanotech $R \& D$ project within a strategic time frame to attain specified commercial objectives. A strong value network and long-term $R \& D$ collaboration among nanotech firms are more likely to be negatively affected if there are high levels of functional closeness within the partnership. We argue that the absence of institutional diversity impedes the overall ability of the collaborative partnership to maintain a steady development of new and innovative products or secure exclusive rights to intellectual property.

\subsection{Cultural dimensions}

The level of tolerance for uncertainty within a nation reveals their cultural attitude towards risks and ambiguity (Sriwindono and Yahya, 2012). A country with a high uncertainty avoidance index is more likely to have rigid belief systems that are intolerant of unorthodox and risky behaviors, because the majority of people with such cultural values are sensitive to, and feel uncomfortable with, unstructured or changeable environments. However, a low uncertainty avoidance index evinces that members of a society are more likely to be forbearing towards ambiguous or uncertain $R \& D$ ventures, because they are entrepreneurial in nature and are likely to feel comfortable in risky and less structured environments. In these countries, nanotech R\&D project managers can take advantage of the politically active and informed populations by making quick decisions that exploit innovative concepts.

Feminine values are another important cultural trait to seriously consider, as this trait affects the dimensions of collaborative partnerships in nanotech R\&D projects. A high proportion of female involvement in science and technology within a country would more likely increase the strength of value networks and reduce the time period of collaborative partnerships in nanotech $\mathrm{R} \& \mathrm{D}$ projects. In contrast, a more dominant male presence usually leads to ego-oriented interfirm relationships that promote fierce competition and focus on profit maximization, irrespective of the impact on the external environment. Cultural values do not easily change in the short run and are usually passed from one generation to another, so it is expedient for policymakers and corporate strategists interested in nanotech R\&D collaborations to understand the possible implications and predictable behaviors relating to risk tolerance, procedural controls, and adherence to norms within a community that they operate in, so as to promote discussions that alleviate unproven claims, improve negotiating processes, and reduce litigation costs (Hong, Heikkinen, and Blomqvist, 2010).

\subsection{Economic growth}

Periods of economic growth positively affect the size, mechanism, strength and timeframe of collaborative partnerships in nanotech R\&D projects, as a result of the availability of several funding prospects, the prevalence of commercial opportunities, and the rise in labor participation. In knowledge-based economies, the expansion of economic activities usually 
leads to a rise in $R \& D$ expenditures. Most universities normally obtain huge funds from research councils and industry partners to finance their R\&D projects, with the aim of building innovation centers and fostering regional economic development (This corresponds with the findings of Bilbao-Osorio and Rodriguez-Pose, 2004; Guerrero, Cunningham, and Urbano, 2015).

The university-industry collaborative partnership is a key ingredient that stimulates productivity in innovative ventures (Jong and Slavova, 2014) and accelerates the growth of economic activities in advanced countries. An increase in the external R\&D activities of high tech firms has resulted in the rapid rise of inter-organizational relationships, which lead to patent licensing agreements and the development and production of new products. The commercialization of $\mathrm{R} \& \mathrm{D}$ activities via university-industry collaborative partnerships has brought not only economic development but also the technological advancement of nations, due to the international demand for their high-tech products, which are usually emerging or disruptive know-how. Having exclusive rights to an innovative product in the form of a patent provides nanotech firms with the required protection for their intellectual property and encourages more $R \& D$ projects in the future.

\subsection{Technological advancement}

As a result of globalization, many countries have been able to unlock localized industries by taking advantage of new and existing export opportunities for high-tech products and services around the world (Mehta et al. 2012). World trade organization has alleviated most barriers and challenges in international commerce, as advanced nations and large corporations are able to attract high-skilled labor and sophisticated investments into emerging and disruptive industries to provide technologically-advanced products and services for worldwide consumption. The export demand for high-tech products evinces the level of technological advancement in a country. Most MNCs have their internal R\&D capabilities at their headquarters, and many external R\&D projects are organized in their home country. Nanotech firms that operate in advanced technological nations are more likely to sell their newly developed innovative products to international markets. They are also more likely to spend less time in collaboration, due to their centralized governance mechanisms and comprehensive value networks.

\section{Conclusion}

Collaboration in nanotech R\&D projects usually involves large funds and expertise, which divert managerial resources away from internal $R \& D$ projects. Institutionalizing collaborative partnerships is extremely challenging, because $R \& D$ projects demand new organizational structures and procedures that harness available resources to achieve set objectives. Our study shows that large nanotech R\&D organizations have fewer industrial partners who spend less time to develop new products, due to their strong value networks and centralized systems of governance in collaborative partnerships. Meanwhile, smaller nanotech R\&D firms require more time and a greater number of industrial partners to develop new products, as a result of their willingness to impose a decentralized organizational structure in R\&D collaborative partnerships.

As a discontinuous innovation-based technology, nanotechnology has few laws that regulate its industry. It requires highly skilled scientists from different disciplines to work in close proximity and operate complex instruments to create innovative new products within a 
specified period of time. Nanotechnology is an interdisciplinary field that requires a great deal of physical closeness among R\&D partners, despite the advancements in ICT as well as the free movement of capital and labor across Europe. Globalisation has helped many countries to unlock localized industries, by taking advantage of new and existing export opportunities for high-tech products across the globe. Advanced nations and large corporations are able to attract high skilled labor and sophisticated investments into emerging and disruptive industries to provide technologically advanced products and services for worldwide consumption. The European Commission has briskly funded inter-firm R\&D collaboration through its Framework Programme for research and technological development.

Certain legal systems, which provide both a greater level of flexibility for securing patents and a higher level of predictability for estimating litigation outcomes, are likely to be more appealing to nanotech $R \& D$ project managers, because there is little regulation restricting the nature and scale of research exploration and commercial exploitation or that could pose a huge threat and the possibility of large losses. However, a collaborative partnership among nanotech organizations could be employed as a market entry corporate strategy into tightly controlled industries to circumvent regulatory constraints. Countries with high uncertainty avoidance index are more likely to have rigid belief systems that are intolerant of unconventional and hazardous behaviors, because the majority of the population feel anxious about unpredictable environments. In countries that seem to have a low level of uncertainty avoidance, most members of their public are more likely to be tolerant towards ambiguous or uncertain $\mathrm{R} \& \mathrm{D}$ ventures because of their entrepreneurial mindset, which is at ease with risky and unstructured environments. Also, a high proportion of female involvement in science and technology within a country would likely increase the strength of value networks and reduce the period of collaborative partnerships in nanotech R\&D projects. Culture doesn't change easily and is usually inter-generational, providing an understanding of the possible consequences and predictable behaviors relating to risk tolerance, procedural controls, and adherence to norms within a community - suggesting a need to encourage public debate and general awareness.

Universities involved in discontinuous innovation-based $R \& D$ projects have specialized interdisciplinary centers, which are capable of collaborating with more industrial partners because of their access to additional financing. Patents and other intellectual property should be used to meet the needs of low-end and prospective customers. Also, academic institutions are now benefiting from the legitimate financial considerations of supplementing patents with publications. The existence of $\mathrm{VC}$ funding in nanotech $\mathrm{R} \& \mathrm{D}$ projects indicates that there are significant commercial opportunities available, and that entrepreneurial prowess is prevalent in such collaborative partnerships.

There are other significant variables, not included in this model, that influence the ability of nanotech companies to collaborate with a large number of industrial partners. Certain key features of a company - such as its age, size, market position, and financial status - could be useful tools for predicting the propensity to enter successful collaborative partnerships. A much larger sample size, incorporating more countries in which nanotech companies operate, would provide useful insights into the legal and cultural determinants of the level, size, and timing of collaborative partnerships. 


\section{References}

Autant-Bernard, C., Billand, P., Frachisse, D., and Massard, N. (2007). Social distance versus spatial distance in R\&D cooperation: Empirical evidence from European collaboration choices in micro and nanotechnologies. Journal of Regional Science 86(3); 495-519.

Balland, P. (2012). Proximity and the evolution of collaboration networks: evidence from research and development projects within the global navigation satellite system (GNSS) industry. Regional Studies 46(6); 741-756.

Basu, S. and Yoshida, R. (2013). How to overcome the cultural divide?: A study of Japanese expatriates' work experiences in India. South Asian Journal of Business and Management Cases 1(2); 115-133.

Beaudry, C. and Allaoui, S. (2012). Impact of public and private research funding on scientific production: the case of nanotechnology. Research Policy 41(9); 1589-1606.

Beck, T., Demirgüç-Kunt, A., and Levine, R. (2003). Law and finance: why does legal origin matter? Journal of Comparative Economics 31(4); 653-675.

Beers, C. and Zand, F. (2014). R\&D cooperation, partner diversity, and innovation performance: an empirical analysis. Journal of Product Innovation Management 31(2), 292-312.

Belin, E. and Monteil, J.M. (1999). Functional proximity as an indicator of interpersonal attraction: Pilot studies. International Review of Social Psychology 12(2), pp.7-24.

Bilbao-Osorio, B. and Rodriguez-Pose, A. (2004). From R\&D to innovation and economic growth in the EU. Journal of Urban and Regional Policy 35(4); 434-455.

Bjorkman, I., Stahl, G.K. and Vaara, E. (2007). Cultural differences and capability transfer in crossborder acquisitions: the mediating roles of capability complementary, absorptive capacity, and social integration. Journal of International Business Studies 38(4); 658-672.

Boschma, R.A. (2005). Proximity and Innovation: A critical assessment. Regional Studies 39(1); 6174.

Bosley, D.S. (1993). Cross-cultural collaboration: Whose culture is it, anyway? Technical Communication Quarterly 2(1), 51-62.

Broocks, A. and Van Biesebroeck, J. (2017). The impact of export promotion on export market entry. Journal of International Economics 107(1); 19-33.

Cavusgil, S.T. and Kirpalani, V.H. (1993). Introducing products into export markets: success factors. Journal of Business Research 27(1); 1-15.

Charles, (2004). An article by HRH: The Prince of Wales on nanotechnology, the Independent on

Sunday. Available on: https://www.princeofwales.gov.uk/media/speeches/article-hrh-the-prince-of-

wales-nanotechnology-the-independent-sunday.

Chua, R.Y.J., Morris, M.W. and Mor, S. (2012). Collaborating across cultures: Cultural metacognition and affect-backed trust in creative collaboration. Organisational Behaviour and Human Decision Processes 118(2); 116-131.

Contractor, F.J. and Lorange, P. (2002). The growth of alliances in the knowledge-based economy. International Business Review 11(4); 485-502.

Cooray, A. (2011). The role of the government in financial sector development. Economic Modelling 28(3), 928-938.

Corbett, J., McKeown, P., Peggs, G. and Whatmore, R. (2000). Nanotechnology: international developments and emerging products. Manufacturing Technology 49(2); 523-545.

Cumming, D. (2008). Contracts and Exits in Venture Capital Finance. The Review of Financial Studies 21(5); 1947-1982.

Cunningham, S.W. and Werker, C. (2012). Proximity and collaboration in European nanotechnology. Papers in Regional Science 91(4); 723-742.

Curzi, D. and Olper, A. (2012). Export behaviour of Italian food firms: Does product quality matter? Food Policy 37(5); 493-503.

Djankov, S., La Porta, R., Lopez-de-Silanes, F. and Shleifer, A. (2008). The law and economics of selfdealing. Journal of Financial Economics 88(3); 430-465.

Eckel, C. and Neary, J.P. (2010). Multi-product firms and flexible manufacturing in the global economy. The Review of Economic Studies 77(1); 188-217.

Ewing, R.D. (2004). Private equity in China: Risk for reward. China Business Review 31(4); 48-52. 
Faems, D., Looy, B.V. and Debackere, K. (2005). Interorganizational collaboration and innovation: Toward a portfolio approach. The Journal of Product Innovation Management 22(3); 238-250.

Fajgelbaum, P., Grossman, G.M. and Helpman, E. (2011). Income distribution, product quality and international trade. Journal of Political Economy 119(4); 712-765.

Fiedler, M. and Welpe, I.M. (2010). Antecedents of cooperative commercialisation strategies of nanotechnology firms. Research Policy 39(3); 400-410.

Franke, R.H., Hofstede, G. and Bond, M.H. (1991). Cultural roots of economic performance: A research note. Strategic Management Journal 12; 165-173.

Gompers, P. and Lerner, J. (2001). The venture capital revolution. The Journal of Economic Perspectives 15(2); ‘ $45-168$.

Guan, J. and Ma, N. (2003). Innovative capacity and export performance of Chinese firms. Technovation 23(9); 737-747.

Guerrero, M., Cunningham, J.A., and Urbano, D. (2015). Economic impact of entrepreneurial universities' activities: An exploratory stud of the United Kingdom. Research Policy 44(3); 748764.

Gulati, R. (1998). Alliances and Networks. Strategic Management Journal 19(4); 293-317.

Hagedoorn, J. (2002). Inter-firm partnerships: an overview of major trends and patterns since 1960. Research Policy 31(4); 477-492.

Heinze, T. (2004). Nanoscience and nanotechnology in Europe: analysis of publications including comparisons with United States. Nanotechnology Law \& Business 1(4); 1-19.

Hofstede, G. (1983). National cultures in four dimensions: A research-based theory of cultural differences among nations. International Studies of Management \& Organization 1(2); 46-74.

Hofstede, G. (1994). The business of international business is culture. International Business Review $3(1) ; 1-14$.

Hong, J., Heikkinen, J., and Blomqvist, K. (2010). Culture and Knowledge Co-Creation in R\&D Collaboration between MNCs and Chinese Universities. Knowledge and Process Management $17(2) ; 62-73$.

Jong, S. and Slavova, K. (2014). When publications lead to products: the open science conundrum in new product development. Research Policy 43(4); 645-654.

Kabo, F.W., Cotton-Nessler, N., Hwang, Y., Levenstein, M.C. and Owen-Smith, J. (2014). Proximity effects on the dynamics and outcomes of scientific collaborations. Research Policy 43(9); 14691485.

Katz, J.S. (1994). Geographical proximity and scientific collaboration. Scientometrics 31(1); 31-43.

Kaufmann, A. and Todtling, F. (2002). How effective is innovation support for SMEs? An analysis of the region of upper Austria. Technovation 22(3); 147-159.

Kica, E. and Bowman, D.M. (2012). Regulation by means of standardization: key legitimacy issues of health and safety nanotechnology standards. Jurimetrics 53(1); 11-56.

Knoben, J. and Oerlemans, L.A. (2006). Proximity and inter-organisational collaboration: A literature review. International Journal of Management Reviews 8(2); 71-89.

Koc, T. and Ceylan, C. (2007). Factors impacting the innovative capacity in large-scale companies. Technovation 27(3); 105-114.

Koch, A. and Strotman, H. (2006). Determinants of innovative activity in newly founded knowledge intensive business service firms. Entrepreneurship in the Region, 195-224.

Kostoff, R.N., Koytcheff, R.G., and Lau, C.G.Y. (2007). Global nanotechnology research literature overview. Technology Forecasting and Social Change 74(9); 1733-1747.

Kumar, K. and Dissel, H.G. (1996). Sustainable collaboration: Managing conflict and cooperation in interorganizational systems. MIS Quarterly 20(3); 279-300.

La Porta, R., Lopez-de-Silanes, F., Shleifer, A. and Vishny, R. (1999). The quality of government. The Journal of Law, Economics, and Organization 15(1), 222-279.

La Porta, R., Lopez-de-Silanes, F., Shleifer, A. and Vishny, R. (2000). Investor protection and corporate governance. Journal of financial economics 58(1), 3-27.

La Porta, R., Lopez-de-Silanes, F., and Shleifer, A. (2008). The economic consequences of legal origins. Journal of Economic Literature 46(2); 285-332.

Lee, Y.S. and Bozeman, B. (2005). The impact of research collaboration on scientific productivity. Social Studies of Science 35(5); 673-702. 
Lindsay, J. and Hopkins, M. (2010). From Experience: Disruptive Innovation and the need for Disruptive Intellectual Asset Strategy. Journal of Product Innovation Management 27(2); 283-290.

Lundquist, K. and Trippl, M. (2011). Distance, proximity and types of cross-border innovation systems: A conceptual analysis. Regional Studies 47(3); 450-460.

Lynch, R.P. (1990). Building Alliances to Penetrate European Markets. Journal of Business Strategy 11(2); 4-8.

Mancinelli, S. and Mazzanti, M. (2009). Innovation, networking and complementarity: Evidence on SME performances for a local economic system in North-Eastern Italy. The Annals of Regional Science 43(3), 567-597.

Mehta, A., Herron, P., Motoyama, Y. Applebaum, R. and Lenoir, T. (2012). Globalization and deglobalization in nanotechnology research: the role of China. Scientometrics 93(2); 439-458.

Miyazaki, K. and Islam, N. (2007). Nanotechnology systems of innovation - An analysis of industry and academia research activities. Technovation 27(11); 661-675.

Monge, P.R. and Kirste, K.K., (1980). Measuring proximity in human organization. Social Psychology Quarterly 110-115.

Moodysson, J. and Jonsson, O. (2007). Knowledge collaboration and proximity: The spatial organization of biotech innovation projects. European urban and regional studies 14(2), 115-131.

Muldur, U. et al. (2007). A new deal for an effective European research policy: The design and impacts of the $7^{\text {th }}$ Framework Programme. Springer Science \& Business Media.

Niesten, E. and Jolink, A. (2014). The impact of alliance management capabilities on alliance attributes and performance: a literature review. International Journal of Management Reviews 17(1); 69-100.

OECD (1997). National Innovation Systems, Paris.

OECD (2014). Nanotechnology in the context of technology convergence.

Paier, M. and Scherngell, T. (2011). Determinants of collaboration in European R\&D networks: empirical evidence from a discrete choice model. Industry and Innovation 18(1); 89-104.

Park, G. and Kang, J. (2013). Alliance Addiction: Do Alliances create real benefits? Creativity and Innovation Management 22(1); 53-66.

Ponds, R., Oort, F., and Frenken, K. (2007). The geographical and institutional proximity of research collaboration. Papers in Regional Science 86(3); 424-443.

Rijnsoever, V.F.J. and Hessels, L.K. (2011). Factors associated with disciplinary and interdisciplinary research collaboration. Research Policy 40(3); 463-472.

Romig Jr., A.D., et al., (2007). An introduction to nanotechnology policy: opportunities and constraints for emerging and established economies. Technological Forecasting and Social Change 74(9); 1634-1642.

Rosenfeld, S.A. (1996). Does cooperation enhance competitiveness? Assessing the impacts of interfirm collaboration. Research Policy 25(2); 247-263.

Rothwell, R. and Dodgson, M. (1991). External linkages and innovation in small and medium $\square$ sized enterprises. R\&D Management, 21(2), 125-138.

Royal Society (Great Britain), (2004). Nanoscience and Nanotechnologies: Opportunities and Uncertainties: Summary and Recommendations. Royal Society.

Sargent Jr, J.F., 2016. Nanotechnology: a policy primer.

Scandura, A. (2016). University-industry collaboration and firms' R\&D effort. Research Policy 45(9); 1907-1922.

Schertler, A. and Tykvová, T. (2012). What lures cross-border venture capital inflows? Journal of International Money and Finance 31(6); 1777-1799.

Schleimer, S.C. and Faems, D. (2016). Connecting interfirm and intrafirm collaboration in NPD projects: Does innovation context matter? The Journal of Product Innovation Management 33(2); 154-165.

Schott, T. (1991). The world scientific community: globality and globalisation. Minerva: A Review of Science, Learning and Policy 29(4); 440-462.

Schummer, J. (2004). Multidisciplinarity, interdisciplinary, and patterns of research collaboration in nanoscience and nanotechnology. Scientometrics 59(3); 425-465.

Shea, C.M., Grinde, R. and Elmslie, B. (2011). Nanotechnology as general-purpose technology: empirical evidence and implications. Technology Analysis \& Strategic Management 23(2); 175-192. 
Spamann, H. (2009). The "antidirector rights index" revisited. The Review of Financial Studies 23(2); 467-486.

Sriwindono, H. and Yahya, S. (2012). Toward Modeling the Effects of Cultural Dimension on ICT Acceptance in Indonesia. Social and Behavioural Sciences 65(2012); 833-838.

Steinmo, M. and Rasmussen, E. (2016). How firms collaborate with public research organisations: The evolution of proximity dimensions in successful innovation projects. Journal of Business Research 69(1); 1250-1259.

Strulik, H. (2005). The role of human capital and population growth in R\&D-based models of economic growth. Review of International Economics 13(1); 129-145.

Teece, D.J. (1993). Profiting from technological innovation: implications for integration, collaboration, licensing and public policy. Research Policy 15(5); 285-305.

Todeva, E. and Knoke, D. (2005). Strategic Alliances and models of collaboration. Management Decision 43(1); 123-148.

Torre, A. (2008). On the role played by temporary geographical proximity in knowledge transmission. Regional Studies 42(6); 869-889.

Wagner, C.S. and Leydesdorff, L. (2005). Network structure, self-organisation, and the growth of international collaboration in science. Research Policy 34(10); 1608-1618.

Wang, L. and Wang, S. (2011). Cross-border venture capital performance: Evidence from China. Pacific-Basin Finance Journal 19(1); 71-97.

Wong, P.K., Ho, Y.P. and Chan, C.K. (2007). Internationalization and evolution of application areas of an emerging technology: the case of nanotechnology. Scientometrics 70(3); 715-737.

Zheng, J., Zhao, Z., Zhang, X., Chen, D., and Huang, M. (2014). International collaboration development in nanotechnology: a perspective of patent network analysis. Scientometrics 98(1); 683-702. 